\title{
ACOLHIMENTO SOLIDÁRIO COMO DISPOSITIVO PARA A FORMAÇÃO PELO TRABALHO: A EXPERIÊNCIA DA DISCIPLINA TRABALHO DE CAMPO II, NO CURSO DE MEDICINA DA UFF
}

\author{
Solidarity as host device Training at Work: the experience of work \\ discipline Course II, the Medical Course at UFF
}

\section{Túlio Bastista Franco}

Doutor em Saúde Coletiva, Professor do Instituto de Saúde Coletiva, Universidade Federal Fluminense.

E-mail: tuliofranco@gmail.com

\section{Resumo}

Este artigo discute a formação em saúde, em especial a formação médica, partindo do pressuposto de que a exposição aos cenários de produção do cuidado é um importante fator de aprendizagem. Por aprendizagem entende-se o processo de cognição e subjetivação ao qual a pessoa produz, ou seja, algo que acontece no campo da razão e também dos afetos. $O$ desafio proposto é o de pensar a formação para o terceiro gênero do conhecimento, de acordo com as categorias propostas por Espinosa, ou seja, um saber que opera pela "ciência intuitiva", onde habita a possibilidade da criatividade nos atos de trabalho em saúde. Para discutir este tema o texto relata a experiência da disciplina de TCSII, no curso de medicina da UFF, o qual utiliza do projeto "Acolhimento Solidário" como um dos dispositivos da educação médica na atenção básica.

Palavras-chave: Educação em saúde; Formação médica; Acolhimento; Trabalho em saúde.

\section{Abstract}

This article discusses the health professionals education, and the medical education in particular, assuming that exposure to the care production scenarios is an important factor in learning. 
Learning, here, is comprehended as the process of cognition and subjectivation to which a person produces, in other words, it is something that happens on the field of reason and also of affections. The proposed challenge is to think about education for the third gender of knowledge, according to the categories proposed by Spinoza, that is, a knowledge that operates by "intuitive science" where the possibility of creativity in health work acts resides. To discuss this, the text reports the experience of the discipline "TCSII" in the medical undergraduate course at UFF, which uses the "Solidary user embracement" project as one of the devices of medical education in primary care.

Keywords: Health education; Medical education; User embracement; Health work.

\section{Introdução}

O desafio deste artigo é discutir um processo de educação capaz de formar pessoas para o pensamento criativo, e assim operar no campo da "ciência intuitiva", associada ao pensamento científico, ou seja, ela compõe com a ciência, agregando novas possibilidades na produção do conhecimento. Seria uma educação capaz de articular ao mesmo tempo um processo de cognição e de subjetivação. Isso só ocorre com base na experiência, ou seja, a exposição máxima aos cenários e práticas de cuidado.

Que educação é esta, poderíamos nos perguntar, que seja capaz de produzir uma transformação nas subjetividades? Entendemos que um processo de educação na saúde só teria sentido se conseguisse operar mudanças, a formação de um novo sujeito capaz de intervir sobre o seu micro-cosmo e nele produzir um mundo conectado com os valores do humanismo, da solidariedade, necessários às práticas de cuidado.
$O$ terceiro gênero de conhecimento ${ }^{1}$ diz respeito àquele que opera no campo da "ciência intuitiva", ou seja, o conhecimento que se produz por relações sócio-afetivas, e que é aprendido portanto pelo corpo afetivo. Esse tipo de saber carece de reconhecimento na atualidade, pois foi consagrado na modernidade, em especial a partir do século XVII o conhecimento científico, ou, na classificação Espinosana o segundo gênero de conhecimento. $O$ saber que se produz ao explicar os acontecimentos com base na ciência e no exercício da razão. Resta ainda segundo o autor ${ }^{1}$ o primeiro gênero de conhecimento, ou, o que vai chamar de "ideia inadequada", o que tem um entendimento parcial ou equivocado dos fenômenos. O terceiro gênero é aquele que permite maiores graus de liberdade, e o pensamento criativo, livre das amarras que em geral submetem o pensamento e as ações das pessoas.

Tomando por referência a teoria de afecção do Espinosa ${ }^{2}$, que atribui ao corpo e sua capacidade de afetar e ser afetado a fonte de aprendizagem. Uma aprendizagem pelos afetos toma o corpo sensível, e como resultado o aumento ou redução da sua potência de agir no mundo. Diz assim o texto:

(...) quando encontramos um corpo exterior que não convém ao nosso (isto é, cuja relação não se compõe com a nossa), tudo ocorre como se a potência desse corpo se opusesse à nossa potência, operando uma subtração, uma fixação; dizemos nesse caso que a nossa potência de agir é diminuída ou impedida, e que as paixões correspondentes são de tristeza. Mas, ao contrário, quando encontramos um corpo que convém à nossa natureza e cuja relação se compõe com a nossa, diríamos que sua potência se adiciona à nossa: as paixões que nos afetam são de alegria, nossa potência de agir é ampliada ou favorecida. . $^{233-34}$ 
O que o autor ${ }^{2}$ vai nos ofertar é a ideia de que a vida se produz por múltiplos encontros, aos quais estamos expostos diariamente, e, tomando o poder de afetar dos corpos, há um permanente efeito sobre os mesmos, que significa um contínuo e ilimitado processo de mudança nas subjetividades. Estamos, portanto, sujeitos às subjetivações, e à permanente variação do grau de potência para agir no mundo, conforme as afecções são de alegria (aumento desta potência) ou tristeza (com redução desta potência).

Ora, o que propomos na exposição do aluno aos cenários da atenção básica é a produção do efeito do seu encontro com a realidade social, a alteridade dos trabalhadores e usuários, a experimentação do estrangeirismo desta nova realidade "em nós". É no estranhamento do encontro, e de si mesmo, que se processa a mudança da subjetividade, muitas vezes formada com base na representação social da medicina e do médico, construção imaginária de um tipo idealizado que muitas vezes não corresponde à prática cotidiana no Sistema Único de Saúde.

Com base numa ideia ${ }^{1}$, podemos referir ao encontro como disparador de processos de subjetivação, portanto, fator de aprendizagem intensiva. Uma aprendizagem que se dá pelo corpo sensível, porque se aprende pelos afetos, associados a um suposto saber. Está se referindo a uma forma de educação com base nas vivências e exposição ao mundo da vida, à experimentação, que é capaz de atravessar o corpo modificando-o, e não apenas um aprendizado cognoscente, que se refere à representação do mundo, já modificado pelos filtros naturais da razão. Para que fique claro, o corpo sensível, ou, Corpo Sem Órgãos (CSOs) ${ }^{3}$, não substitui, ou, se coloca em oposição à ideia de Corpo com Órgãos, ou, corpo biológico, as duas dimensões estão presentes no mesmo organismo. A questão central é que o CSOs carece de reconhecimento, e, é preciso além de reconhecê-lo entender que ele tem força operatória sobre a realidade, assim como é afetado, também produz o seu microcosmo.

Estas questões vão nos remeter ao que temos sugerido para a prática da educação permanente (EP), entendendo-a como uma ferramenta que reúne as várias pedagogias ativas, pois, a EP é antes de tudo ativada pelo encontro e a experimentação do trabalho como principal insumo do ensino e aprendizagem, e, por isto, capaz de operar um aprendizado pela razão e pelo corpo afetivo.

Não propomos uma separação ou juízo de valor sobre práticas cognitivistas ou sócio-afetivas para a educação, entendemos que práticas educacionais em geral podem operarnestas duas dimensões, elasconvivem nos mesmos processos e ao mesmo tempo, sob uma tensão que se manifesta como campo de luta entre o pensamento e prática instrumental, e ao mesmo tempo outro campo que toma os afetos como problema da sua construção. Isto se materializa em pedagogias ativas, que expõe o sujeito ao mundo da vida, dispara processos de análise e autoanálise que envolve a si e sua relação com a realidade. Haverá sempre uma tensão a constituir estas relações, que podem capturar para o campo cognitivista simplesmente, o que há de liberdade e criação na função pedagógica do ensino, ou, produzir uma relação pedagógica que opera por pressupostos filosóficos que conduzem à constituição de um novo "modo de funcionamento do saber", capaz de constituir, de formar o pensamento criativo. A questão central portanto está nas opções éticas, estéticas e políticas para a condução dos processos educacionais.

É com base nestas questões que vamos propor o ensino na graduação que toma por principal referência a "pedagogia do fator de exposição" proposta pelo projeto CINAEMi ,

\footnotetext{
Comissão Interinstitucional Nacional de Avaliação do
} 
em uma aposta de que a exposição aos cenários de práticas, incluindo os próprios usuários e seus problemas de saúde, é fator de aprendizagem intensiva, capaz de operar no aluno recursos cognitivos, ou seja, formação de um saber, e ao mesmo tempo, produzindo processos de subjetivação capazes de fazer com que ele interprete a realidade com a qual está em contato, de um jeito específico, na medida em que esta experiência, como já disse, o atravessa, modificando-o, pelas afecções de que este encontro é capaz de produzir. O fator de exposição se associa à problematização ${ }^{4}$, à aprendizagem significativa e a todas as formas de ativismo na relação ensinoaprendizagem, que seja possível acionar com o aluno.

Com base nesses pressupostos é que propomos o uso das ferramentas da Educação Permanente, no cenário da atenção básica, para a formação nos cursos da área de saúde. Este texto pretende discutir o processo de ensino-aprendizagem com base na experiência do Curso de Medicina da Universidade Federal Fluminense (UFF), especificamente na disciplina de Trabalho de Campo Supervisionado II (TCSII), ministrada no 3 ㅇ e 4 períodos. Supomos assim que o processo pedagógico tenha por objetivo não apenas o saber, mas este utilizado como ferramenta para intervenções no mundo, o que significa, operar ao mesmo tempo a produção de um conhecimento, mas também, a formação de sujeitos com uma certa ética de cuidado, através de processo de subjetivação.

Ensino Médico. Projeto de intervenção participativa e auto sustentada, que tem como objetivos gerais estimular a manutenção e ampliação do movimento social desenvolvido nas fases anteriores do Projeto CINAEM e promover a transformação da escola médica de acordo com novos paradigmas, capazes de viabilizarem a formação de um médico adequado as demandas sociais contemporâneas e competente o suficiente para influir positivamente na implantação e consolidação de políticas de saúde de relevância atual (AU). (Bireme/Lilacs-acesso em agosto de 2013).
Estamos diante de duas questões envolvendo intervenções na rede básica de saúde, quais sejam: primeira diz respeito a que ética do cuidado nos referenciamos, ou, desejamos formar os futuros profissionais. Segunda, que pedagogia devo utilizar, ou, como conduzir o processo de aprendizagem.

\section{Produção do Aprendizado por Quem Aprende: produção de $\mathrm{Si}$}

A Unidade Básica de Saúde à qual nos referimos aqui, localiza-se em NiteróiRJ, e tem uma área de abrangência que confere dois setores, com duas microáreas cada um, ressaltando que essas microáreas são bastante heterogêneas. O território atendido pela unidade apresenta favelas, e cortiços, retratando condições precárias de qualidade de vida, entre casas de classe média, caracterizando forte desigualdade social.

Um grupo de 8 alunos, acompanhado pelo professor, faz sua disciplina nestaUnidade, acompanhando os trabalhos dos profissionais, incluindo visitas domiciliares. Num certo período as visitas foram interrompidas por conflito no morro entre dois grupos rivais, o que tornou as condições de segurança muito precárias. Assim os alunos ficaram sem possibilidade de acesso aos moradores no seu local de moradia. Foi diante deste impasse que fiz a seguinte reflexão com os alunos: "o morro desce na Unidade todos os dias, através dos usuários. Se conseguirmos narrativas de suas vidas, vamos entender as suas condições de existência". Foi a partir desta conversa que propus o projeto "Acolhimento Solidário" a ser desenvolvido pelos alunos. O mesmo consiste no seguinte: 


\section{O Projeto Acolhimento Solidário}

O Projeto Acolhimento Solidário foi elaborado segundo programa da disciplina TCSII, do Curso de Medicina da UFF, e tem como objetivo fazer com que os alunos de medicina apreendam sobre a organização e funcionamento da atenção básica à saúde, os processos de trabalho, condições socioeconômicas da população, principais demandas à Unidade de Saúde, práticas de cuidado centradas nas tecnologias leves, especialmente o exercício do acolhimento.

Para isto os estudantes deve ter a habilidade para a escuta qualificada do problema de saúde dos usuários, e saber iniciar e conduzir uma entrevista com estes, no cenário da Unidade de Saúde.

\section{Diretrizes Pedagógicas}

Partimos da ideia inicial das pedagogias ativas, onde o aluno vira protagonista, sujeito do seu próprio processo de aprendizagem, e associamos a esta ideia a defendida pelo projeto CINAEM que proponha a reforma da escola médica nos anos 1990, e formulou a ideia de "pedagogia do fator de exposição" para sugerir o máximo de exposição aos cenários de práticas, e adotamos também a problematização de inspiração em Paulo Freire, junto com um esforço de análise das entrevistas diariamente, e do conjunto da atividade ao final.

\section{Preparação}

Para que os alunos assumam o protagonismo desejado no acolhimento, é necessário que eles entendam o conceito e tenham treinamento suficiente para iniciar e conduzir uma entrevista, em sala de espera, estando preparado para enfrentar de forma tranquila e segura, situações inusitadas que aparecem neste cenário. A preparação dos alunos envolve:
1. Compreender o conceito de acolhimento como uma tecnologia relacional de cuidado, que tem como principal dispositivo a escuta qualificada, se colocar no lugar do outro, solidariedade com o que sofre, harmonia nas relações. É ofertado um texto de referência sobre o Acolhimento ${ }^{5}$.

2. Treinar para a escuta qualificada em entrevista na sala de espera, o que significa compreender antecipadamente sobre as condições socioeconômicas da clientela, como iniciar a abordagem (se apresentar, pedir para conversar, etc), como conduzir a entrevista (estar preparado para o inesperado, manter calma e segurança em situações inusitadas, compreender, ser tolerante, aconselhar dentro das ofertas da Unidade).

3. Saber a função do roteiro como instrumento, e portanto secundário à própria relação com o usuário, ou seja, ele é uma referência mas não deve ser entendido como recurso burocrático, é um instrumento que ajuda na conversa. Sendo assim, a primeira questão é para disparar a conversa, não necessariamente se espera uma resposta objetiva. Na conversa devese procurar explorar os elementos a história da pessoa, suas mazelas, sua condição de vida na comunidade, etc. Em segundo lugar vêm os dados de identificação e sócio-econômicos (evitou-se dados mais constrangedores porque os dados não são o foco).

4. Estimular uma "narrativa de histórias de vida" do usuário, porque é pela sua história que se vai conhecer as razões do seu problema de saúde, e dentro da sua história se encontra também a morbidade, ou, aquilo do qual padece.

Tudo isto merece um período de discussão e preparação, porque o senso comum de trabalho do médico, ainda é muito voltado aos procedimentos, com baixo reconhecimento para as tecnologias leves (relacionais). $O$ projeto Acolhimento 
Solidário tenta justamente fazer o inverso, demonstrar que a relação é a chave para um cuidado resolutivo, eficaz e satisfatório.

\section{Fazendo o Acolhimento Solidário}

Aqui reafirmamos a ideia de que o aluno assume uma posição de sujeito do cuidado, protagonista quando assume a relação com o usuário, e por isto ele além de treinamento vai estar sob supervisão do preceptor. Ele nessa posição é alunotrabalhador, dentro da competência adquirida até aqui.

Local: Sala de espera da Unidade de Saúde.

Quem acolhe os usuários: os alunos em duplas. O preceptor mantém uma distância vigiada, ou seja, não fica junto da dupla mas fica na retaguarda.

Início e desenvolvimento: o ideal é que alguém da própria Unidade apresente os alunos e diz aos usuários que estes vão conversar com eles. Em seguida os alunos em duplas vão até os usuários e se apresentam, pergunta se podem conversar, sendo autorizados iniciam com a questão disparadora, e, escuta atenta. Anotação dos dados.

Após as entrevistas: Após as entrevistas em cada dia se reúnem em roda onde cada dupla relata os casos que entrevistou. $O$ preceptor precisa ficar atento para o relator, que às vezes tendem a ser sucintos e resumir ao problema clínico, e, interrogar a dupla sobre a história do usuário, puxar mais conversa, que, geralmente os alunos vão ter mais elementos da própria entrevista que servem para a discussão e análise do seu conteúdo.

\section{Resultados esperados}

A experimentação do trabalho é a grande fonte de conhecimento, e é esta aposta do Acolhimento Solidário, ao propor que o aluno seja ativo, um ator na cena de cuidado na Unidade de Saúde. Sendo ele o condutor da relação com o usuário, se expondo ao risco "de não conseguir", tendo que "encontrar saídas para situações inesperadas", exercendo o raciocínio, sua capacidade relacional, e o conhecimento intuitivo para manejar as situações, sendo cada uma delas, uma novidade. Estas questões operam fortemente no aprendizado. Por exemplo em uma desta situações a aluna fez a pergunta disparadora "por quê a senhora veio na Unidade hoje?" "Para matar a médica", responde a usuária de serviço de saúde mental, em situação de surto. Neste caso a dupla então treinada, manteve a conversa, deixou que a usuária conduzisse a entrevista, e ao final esta foi atendida e encaminhada. A entrevista foi analisada ao final do dia, assim como a brilhante condução dos alunos à situação. Esta usuária foi escolhida para o estudo de caso a ser feito no próximo período pelo grupo.

Espera-se portanto que os alunos após sua participação no projeto:

- entendam sobre o território no qual estes usuários vivem. A experiência conduzida no Morro do Palácio (Niterói) mostrou que, mesmo não podendo ir até o território porque as facções de tráfico estavam conflagradas, o território veio até os alunos através dos relatos dos próprios usuários:

- adquiram conhecimento da história de vida dos usuários, e se tornem sensíveis às suas questões, reconhecendo que ao chegar à Unidade é um problema de saúde e merece atenção e cuidado;

- tenham entendimento do processo de trabalho da equipe da Unidade, compreendendo que as tecnologias relacionais são fundamentais para o cuidado;

- constatem a necessidade de vigilância e promoção da saúde, como dispositivos de cuidado complementares à clínica; 
- compreendam que o cuidado se produz em rede, seja dentro da Unidade entre os trabalhadores, e da Unidade com as outras complementando os serviços. "Uma andorinha só não faz verão";

Enfim...que se tornem acolhedores no seu exercício profissional.

O projeto foi desenvolvido pelos alunos com grande desenvoltura. É o momento em que eles se veem como profissionais, e ao mesmo tempo são aprendizes, mas sob os mestres usuários, pois há o reconhecimento de que estes têm um conhecimento importante a ser considerado, da vida e as condições de existência na sua própria comunidade. $E$ com isto a saúde e a necessidade de cuidado.

No Projeto Acolhimento Solidário são escolhidos alguns usuários para um "estudo de caso" de acompanhamento mais sistemático, para percepção da produção do cuidado. Retratamos aqui um destes estudos realizado com a usuária JMA:

10. Movimento, elegendo um caso para o estudo:

Eleger um usuário para estudo e acompanhamento pelo grupo de alunos é um primeiro exercício importante. Um primeiro critério discutido é o de que interessaria um usuário que tenciona o serviço de saúde, ou seja, não necessariamente alguém que tenha um problema clínico difícil, mas um caso que por alguma razão incomoda os trabalhadores, e sua análise portanto coloca em questão a produção do cuidado nas suas múltiplas dimensões: o processo de trabalho e suas tecnologias, as práticas de cuidado, as redes que se formam entre os trabalhadores e destes com os usuários, etc. Foi por este critério que chegamos à usuária JMA.

A usuária J.M.A reside em uma casa pequena, em um tipo de vila, com pouca iluminação e condições de higiene precárias. Ela tem 22 anos, mora com sua mãe e seus dois filhos, sua primeira gestação foi aos 15 anos. Vida sexual com múltiplos parceiros, e patologia cervical. A usuária possui dificuldade em aderir e responder aos projetos terapêuticos apresentados pela equipe multiprofissional de saúde que a acolhe na unidade.

2‥ Movimento, a definição das necessidades de saúde:

Segundo a taxonomia das necessidades de saúde, elas podem ser divididas em quatro conjuntos: $O$ primeiro conjunto consiste em se ter "boas condições de vida". Outro conjunto representa o acolhimento e a capacidade de se ter acesso aos serviços de saúde e poder, com isso, conquistar uma vida mais prolongada. O terceiro conjunto representa a criação de vínculos afetivos e efetivos entre cada usuário e uma equipe profissional, reconhecendo que esses vínculos significam o estabelecimento de uma relação contínua no tempo, pessoal e intransferível, calorosa: encontro de subjetividades. O quarto de conjuntos de necessidades diz respeito à necessidade de cada pessoa ter graus crescentes de autonomia no seu modo de andar a vida ${ }^{6}$. As necessidades apontadas pelo autor representam a base para se alcançar a integralidade e a equidade na atenção em saúde o que, consequentemente, representa significativas melhoras no quadro de cuidado do usuário. A integralidade é essencial para que seja possível atender as diferentes necessidades que o usuário apresenta. Assim, a classificação destas necessidades é de extrema importância para que existam focos no atendimento em saúde que supram essas necessidades. Esses focos seriam trabalhados por equipes multiprofissionais, buscando uma maior especificidade no cuidado do usuário no que se diz respeito à demanda de suas necessidades quando busca o serviço de saúde.

3‥ Movimento, a narrativa:

A narrativa pode ser obtida livremente 
ou através do fluxograma analisador dos processos de trabalho ${ }^{7,8,9}$. Importa que haja dados da inserção do usuário na rede de saúde, e sobre o seu mundo. A narrativa não dispensa o esforço em estabelecer uma relação com o usuário, escuta qualificada do seu problema e com ele estabelecer um vínculo que permita a confiança, espaços de escuta e fala.

4‥ Movimento, a definição das fontes e produção dos dados:

A produção de dados se dá sobretudo com base em fontes primárias, quais sejam: i) o prontuário. Primeira fonte pesquisada, importa fazer uma discussão com os alunos sobre o seu uso, sua importância e a necessária anotação detalhada de dados. O prontuário atual em geral traz dados muito resumidos, servindo para uma primeira aproximação do caso, mas mantém grandes limites para sua compreensão. ii) entrevistas. Instrumento para obter as narrativas conforme relatado anteriormente. Importa levantar para além do problema clínico propriamente dito, a vivência cotidiana, relações sociais e de família, os estressores do cotidiano, se há um cuidador ou se o mesmo está desamparado. A perspectiva de vida e como esta se produz. iii) visita domiciliar. O lugar de moradia do usuário é sempre muito importante, para conhecimento das suas condições de conforto e segurança no domicílio, quanto para entender as relações de família, fator importante no processo de condução do projeto terapêutico.

Através das fontes de dados, fizemos a análise da produção do cuidado para elaborar o fluxograma descritor. Para este caso, o fluxograma não foi concretizado da forma mais convencional, devido ao fluxo irregular da usuária. Para tanto, descrevemos as diversas interrupções da usuária em forma de diferentes fluxogramas, ressaltando que, diversas vezes, a usuária interrompeu o projeto terapêutico apresentado.
A Linha de Cuidado percorrida por JMA

A usuária J.M.A consta como cadastrada na Unidade de Saúde, desde 2001. No entanto, a partir do dia 13 de fevereiro de 2007, a usuária buscou o posto pedindo orientações sobre métodos contraceptivos, dando início ao seu histórico direcionado para doenças sexualmente transmissíveis e gravidez não planejada. Consta em seu prontuário que sua menarca foi aos 12 anos, e que a sua primeira gravidez foi aos 15 anos. Em fevereiro de 2007, a usuária apresentava seu primeiro filho com 8 meses e estava amamentando-o. A usuária nega tabagismo e não possui histórico de Diabetes Mellitus Gestacional (DMEG). Nesse estágio, a usuária foi direcionada ao uso do contraceptivo depoprovera. Não consta no prontuário que a usuária retornou ao posto para dar continuidade ao seu tratamento contraceptivo.

A partir deste momento a história da usuária é caracterizada por sucessivas Doenças Sexualmente Transmissíveis (DST's), combinadas com co-morbidades, associadas às precárias condições de vida, exposição a ambiente insalubre, alto consumo de álcool. Há sucessivos esforços de convencimento da usuária para adesão ao tratamento sugerido pelo médico, incluindo de tuberculose, sendo que a usuária tem se negado a comparecer à Unidade de Saúde, se permitindo o cuidado apenas quando o problema se torna agudo.

A visita domiciliar forneceu a imagem de condições precárias de higiene e, em conversa com a mãe, esta informa uso constante e exagerado de álcool pela usuária, sendo que o pai de um de seus filhos estaria envolvido com o tráfico de drogas. A mãe demonstrou gratidão pela preocupação do médico com a filha e afirmou ser realmente difícil convencê-la de ir a unidade cumprir com seu projeto terapêutico, evidenciando a complexidade do caso. 


\section{Discussão da experiência}

O que se expressa no caso a partir da experiência é o Trabalho e Educação como instâncias do cuidado e da aprendizagem, imanentes entre si e inseparáveis, este é o pressuposto que buscamos como base para as discussões relacionadas à educação médica e para as outras profissões de saúde. Em "O Nascimento da Clínica"10, é retratada com clareza a busca do conhecimento pelos médicos, na época sobretudo os cirurgiões e patologistas, através da abertura dos corpos e o ato de "debruçar-se sobre" os mesmos, o exercício clínica, que vem da palavra grega Kliné que significa leito, sendo o médico clínico aquele que se debruça sobre o leito para observar o doente. Foucault seu o nome de "clínica do olhar" a essa primeira perspectiva do trabalho médico. O que tiramos dessa primeira experiência é o aprendizado pela prática, pela experimentação, algo que age sobre o aprendiz com toda intensidade. A educação médica segue esse preceito, ou seja, se os primeiros médicos aprenderam a clínica do olhar sobre os órgãos no corpo então aberto, os aprendizes fizeram os mesmos gestos seguidos pelos seus mestres e assim sucessivamente. $O$ aprendizado é sempre associado a uma prática, sob tutela de um mais experimentado. Mas o que fica de nobre é o aprendizado em ato, em que trabalho e educação estão absolutamente agregados um ao outro.

Como podemos analisar, a narrativa evidencia como J.M.A teve acesso à unidade e como o seu caso foi elaborado pela equipe profissional. A principal dificuldade encontrada é a de que a usuária não colabora com o projeto terapêutico apresentado para seu processo de cuidado. Não é possível afirmar as causas para essa dificuldade mas, se tratando de uma usuária jovem, com dificuldades sociais e econômicas, é possível compreender as barreiras que a impedem de promover o auto-cuidado.
A Unidade Básica de Saúde consegue responder bem às necessidades da usuária, visto que, os medicamentos estiveram sempre disponíveis para ela; as referências, quando necessárias, foram dadas, ainda que a usuária não tenha respondido a isso; a equipe da unidade criou vínculo com a mesma, conhecendo-a bem, assim como o seu contexto familiar e de vida; a usuária teve acesso aos exames que lhes foram pedidos, ainda que a mesma não os tenha realizado por vontade própria todas as vezes que eles foram necessários.

De acordo com os relatos do médico, J.M.A estava ciente da importância de seguir seu projeto terapêutico para a sua saúde. Ainda assim, a mesma permanecia em comportamento difícil, o que dificultou muito a execução desse projeto.

Os relacionamentos da usuária mostraram uma vida conturbada, mediada por perdas e carência econômica, o que pode contribuir muito para seu temperamento difícil, para a falta de perspectiva de vida e, consequentemente, para a dificuldade da promoção do auto-cuidado.

Podemos perceber a importância do vínculo entre o médico e a usuária, e as extensas conversas que o mesmo buscou, almejando encontrar solução para o caso. A usuária obteve total acolhimento na unidade, desde que deu entrada nela, o que é percebido pelo conhecimento que a equipe tem de seu histórico, além da preocupação pela usuária.

Dessa forma, o conteúdo desse caso ressalta o tema integralidade como fator preponderante na construção do histórico da usuária, para melhor compreensão do mesmo. $E$, sendo assim, retorno ao autor $^{6}$ com a seguinte frase: "A busca da integralidade, se levada às últimas consequências, revelaria as diferentes iniquidades vividas por cada um que busca os serviços de saúde." O caso J.M.A nos revelou peculiaridades intrínsecas ao indivíduo estudado que dificulta que os 
serviços de saúde concluam o processo de cuidado.

Especificamente à aprendizagem, a prática de ensino nesta disciplina demonstra que uma Unidade de Produção do Cuidado é ao mesmo tempo uma Unidade de Produção Pedagógica ${ }^{11}$, tomando por referência a ideia de que trabalho e educação são indissociáveis, pois, a atividade produtiva, práxica, o trabalho em si, produzem um conhecimento com base na experimentação, capaz de transformar os sujeitos que dela participam.

Foram importantes o contato com o domicílio da usuária, a sua família e percepção do meio social em que vive. Isto fez com que se compreendesse o fato de que, embora ela tenha sido acolhida na Unidade, e os profissionais tenham encaminhado um projeto terapêutico para seu cuidado, as ferramentas disponibilizadas até então não conseguiram produzir nela uma adesão consistente ao cuidado. Este é o principal desafio.

Os alunos perceberam com clareza o processo de trabalho de cada profissional, e os fluxos assistenciais da Unidade de Saúde. Esses foram bem demonstrados ao estudarem a linha de cuidado da usuária, ficando claro que havia uma disponibilidade em atendê-la e conduzir seu projeto terapêutico, contudo, não se conseguiu atuar sobre sua condição afetiva e social a fim de produzir nela uma vontade de se cuidar. Suas escolhas para a condução da sua vida envolvida um modo de vida de alta exposição ao risco de adoecimento, agravo, e abandono dos filhos. Tudo isto combinado com o abandono de si, por outros e por ela mesma. Estes aspectos que embora entendidos não tiveram uma condução que fosse capaz de altera o modo como caminhava na vida.

Puderam perceber a importância dos cenários de vida e a compreensão sobre as opções para certos modos de vida das pessoas, entendendo que a intervenção sobre o corpo embora importante tem limites, e o conhecimento da saúde requer a ideia de uma "clínica dos afetos"12 como dispositivo do cuidado.

A clínica dos afetos reconhece o encontro como dispositivo do cuidado, e a potência dos corpos como uma força que opera fortemente para o cuidado em saúde. Estes afetos são circulantes também nas relações entre os alunos e os trabalhadores, usuários, as ideias com as quais os alunos se veem expostos no processo de aprendizagem.

\section{Considerações finais}

Podemos concluir afirmando que este processo de aprendizagem se inicia com o dispositivo do encontro, opera no corpoaprendiz e gera efeitos interminavelmente. Por isto qualquer tentativa de concluir pode se frustrar, porque o dispositivo encontro continua agindo indefinidamente nos corpos, e produzindo seus efeitos na mesma intensidade.

A aprendizagem sócio-afetiva é um tipo de educação inconclusa, porque infinita na dimensão temporal, algo que perdura enquanto houver trabalho sendo efetuado pelos que se encontram na cena de produção do cuidado, e, como sugerimos, é também uma cena de produção de saber. Podemos perceber que a dimensão sócioafetiva do trabalho e educação é inseparável da dimensão mais técnica e instrumental, tal como sugerimos o acoplamento do conhecimento de terceiro gênero com o de segundo gênero, ou seja, a "ciência intuitiva" ao "conhecimento científico" ${ }^{1}$. Cabe aos operadores da educação e do cuidado utilizar destas tecnologias na sua prática com a dimensão que lhes cabe, ou seja, sugerimos sempre que a dimensão instrumental da formação e do trabalho esteja subsumida pelo campo cuidador e a implicação dos trabalhadores com seu próprio fazer ${ }^{7}$, e ao mesmo tempo ao campo 


\section{Artigo Original}

dos afetos.

Não há um tipo de trabalho que se qualifica a priori, na saúde ele acontece em ato, na própria relação-encontro com o usuário, por isto os processos educacionais de formação das profissões de saúde, podem resulta em um trabalhador que vai conduzir seu trabalho de forma meramente instrumental, ou, outro que poderá operar as dimensões sociais e afetivas nas relações de trabalho e cuidado. O que virá a ser depende dos aspectos formativos e as subjetividades resultantes dele. Entender esta questão é fundamental para pensar as metodologias de ensino das profissões de saúde.

O Acolhimento ${ }^{5}$ aparece no cenário como um importante dispositivo através do projeto "Acolhimento Solidário", momento em que os estudantes aparecem mais como profissionais, tendo desde já a responsabilidade de estabelecer relações, e operar o exercício da escuta, fala, olhares, e todos aspectos relacionais com o usuário. É no interstício estudante e usuário, no "entre" eles, acontece o cuidado e a aprendizagem, operando assim o processo de formação, mesclado pelo saber já dado, e a "ciência intuitiva", que opera em ato, um conhecimento inusitado, criativo, afetivo, mas igualmente forte na produção de realidade. Esta é a síntese de um processo de formação que ainda procuramos alcançar no campo da educação em saúde.

\section{Referências}

${ }^{1}$ Spinoza, B. Ética. Belo Horizonte: Autêntica; 2008.

2 Deleuze, G. Espinosa filosofia prática. São Paulo: Escuta; 2002.

${ }^{3}$ Deleuze, G. O Anti-édipo. Lisboa: Sírio \& Alvim; 1972.

${ }^{4}$ FREIRE, P. Educação como prática da liberdade. Rio de Janeiro: Paz e Terra, 2003.

${ }^{5}$ Franco, TB; Bueno, WS; Merhy, EE. O Acolhimento e os Processos de Trabalho: o caso de Betim-MG. Cad. Saúde Pública. 1999 abr-jun; 15(2):345-353.

${ }^{6}$ Cecílio, LC de, Oliveira, MHJ Necessidades de saúde das pessoas como eixo a integração e a humanização do atendimento na rede básica. In: Linhares, A L. Saúde e Humanização: a experiência de Chapecó. São Paulo: Hucitec; 2000.

${ }^{7}$ Merhy, EE. Em Busca do Tempo Perdido, a micropolítica do trabalho vivo em saúde. In: Merhy, EE, Onocko, R. Agir em saúde, desafio para o público. São Paulo: Hucitec; 1997: 04-30.

${ }^{8}$ Franco, T B. O Uso do Fluxograma Descritor e Projetos Terapêuticos para Análise de Serviços de Saúde, em apoio ao Planejamento: O caso de Luz - MG. In: O Trabalho em Saúde: olhando e experienciando o SUS no cotidiano. São Paulo: Hucitec; 2003.

${ }^{9}$ Franco, T B, Merhy, EE. O uso de Ferramentas Analisadoras para apoio ao planejamento dos serviços de saúde: O Caso do Serviço Social do Hospital das Clínicas da UNICAMP (CampinasSP). In: O Trabalho em saúde: olhando e experienciando o SUS no cotidiano. 4.ed. São Paulo: Hucitec; 2007.

${ }^{10}$ Foucault, M. O Nascimento da Clínica. Rio de Janeiro: Editora Forense - Universitária; 1980.

${ }^{11}$ Franco, TB. Produção do cuidado e produção pedagógica: integração de cenários do SUS. Interface - Comunic., Saúde, Educ, 2007 sept-dec; 11(23): 427-438.

${ }^{12}$ Franco, TB, Galavote, HS. Em Busca da Clínica dos Afetos. In: Franco, TB, Ramos, VC Semiótica, Afecção e Cuidado em Saúde. São Paulo: Hucitec; 2010. 